\section{Fifty shades of African light- ness: a bio-psychosocial review of the global phenomenon of skin lightening practices}

\author{
Meagan Jacobs, ${ }^{1}$ Susan Levine, ${ }^{2}$ \\ Kate Abney, ${ }^{3}$ Lester Davids ${ }^{1}$ \\ ${ }^{1}$ Redox Laboratory, Department of \\ Human Biology, Faculty of Health \\ Sciences, University of Cape Town, \\ ${ }^{2}$ School of African and Gender Studies, \\ Anthropology and Linguistics, University \\ of Cape Town; ${ }^{3}$ Organization for Tropical \\ Studies, Skukuza, South Africa
}

\section{Abstract}

Skin-lightening is an aesthetic practice of global concern. By adopting a biopsycho-social approach, we consider the interplay between the biological, psychological and social factors that underpin the circulation and consumption of skin lighteners in South Africa. This paper reflects on biological aspects of skin lightening, interpersonal relationships, individual beliefs and expectations about the maintenance of health and well being that informs cosmetic practices. The paper seeks to examine claims made by historians (Thomas) and political philosophers and activists (Biko) that colonialism and apartheid in South Africa historically reinforced the use of skin lightening products in the country. The paper also investigates the role of media in staking out the boundaries of beauty. We argue that men and women practice skinlightening not only as a complex result of the internalization of global standards of beauty, but meshed with a national politics of race and colorism. Banning skin lightening products without understanding the biological effects but also the social forces that underlie their increased popularity will prove futile. Moreover, we must consider the immeasurable pleasures associated with lightening, and the feelings with achieving visibility in South Africa, a country that continues to wrestle with blackness.

\section{Introduction}

Medical experts consider skin-lightening and skin-bleaching practices as 'one of the most common forms of harmful body modification practices ...' (Charles 2003, p. 711). ${ }^{1}$ Melanie De Souza argues that the desire for even-toned, blemish-free skin spans human populations. ${ }^{2}$ Skin-lightening is just one of the multiple options for augmenting the skin's surface appearance, including but not limited to tanning, scarification, makeup, tattooing, face lifts, nose jobs, botox, lip extensions, and piercings. ${ }^{3}$ The desire to change skin colour from darker to lighter or from lighter to darker share an enhanced effect for the consumer, ${ }^{2}$ which has subjective and objective characteristics. This enhanced effect is directed to the way products are marketed that is to achieve a desirable skin colour or to improve an undesirable one. ${ }^{4}$ Ironically, such an enhanced effect is overdetermined by inherent health risks, including skin cancers, steroid-induced acne, atrophy and telangiectasia. ${ }^{5}$ This practice can be traced back to colonialism, a period of institutionalised exploitation by colonists of indigenous populations. During colonisation privileged lighter skin with socioeconomic privilege. This paper traces historical events in South Africa which may have aided or influenced the uptake and use of skin lightening creams.

\section{History of skin lighteners}

While globally, skin lighteners have been used for centuries, the earliest records of their use in South Africa among black women suggest that it began in the 1950 s alongside the Coloured Labour preference Act of 1955.

This racially divisive legislation provided a distinct advantage to coloured individuals over black Africans in relation to employment, accumulation of material wealth and property, and ease of movement, amongst other things. ${ }^{6}$ Black women in the Western Cape Province in particular, were more likely to find employment as domestic workers and cooks if they appeared to have a lighter complexion. ${ }^{7}$ In addition to the racial hierarchy of the apartheid state, colonial histories were dominated by subjective interpretations and morally-coded indictments of race and beauty. ${ }^{8}$ KenyaSue Smart argues that colonial vestiges cast European characteristics of Whiteness with beauty and purity, while Africans were characterised as demonic, ugly savages political, ${ }^{8}$ social and economic ideology premised on racial inferiority The legacy of apartheid in South Africa coupled with westernised ideals of beauty underpins the desire to lighten as a means to overcome institutional forms of discrimination including colour stigma. ${ }^{9}$

Former South African President Thabo Mbeki once referred to Apartheid law (19481994) as Poverty and the rule of race. ${ }^{10}$ Apartheid was a system of governance premised on the oppression of dark-skinned populations by light populations. Racial segregation occurred in almost every domain of public and private life; wherein the minority white population received privileges and rights not available to the majority black population.
Correspondence: Lester M. Davids, Department of Human Biology, Redox Laboratory, Level 6 , Anatomy Building, University of Cape Town, Anzio Road, Observatory, 7925, Cape Town, South Africa.

Tel.: + 021.406678.

E-mail: lesterdavids@gmail.com

Key words: skin-lightening, biological, psychological, social, biopsychosocial, media.

Contributions: the authors contributed equally.

Conflict of interest: the authors declare no potential conflict of interest.

Funding: funding for the research was obtained from the Programme for Enhancement of Research Capacity (PERC) institutional grants to LMD and SL (University of Cape Town, internal fund \#436353).

Received for publication: 5 May 2016.

Revision received: 17 October 2016.

Accepted for publication: 30 November 2016.

This work is licensed under a Creative Commons Attribution NonCommercial 4.0 License (CC BYNC 4.0).

(C)Copyright M. Jacobs et al., 2016

Licensee PAGEPress, Italy

Journal of Public Health in Africa 2016; 7:552 doi:10.4081/jphia.2016.552

Simultaneously, the global media industry fuelled the notion that fair-skinned people were beautiful and thus, a standard was set for beauty. ${ }^{11,12}$ These factors together with trauma of colonization, slavery, discrimination, mistreatment, and colour rating in social class against dark skin continued to be further embedded in the psyche of those with more pigmented skin. In his book, Black skin, white masks, ${ }^{13}$ Franz Fanon draws on his own experiences as a black person in a white dominated world. In his own struggles with stereotypes and prejudices Fanon only wanted to be "oneself with all the multiplicities, systems and contradictions of one's own ways of being, doing and knowing' (1952: pg. VI). ${ }^{13}$ His work which can also be applied to the life of the American popular star Michael Jackson, describes the psychology of blackness and how notions of whiteness are internalized by colonizers as well as the manifestation thereof in the collective black psyche (Supplementary Figure S1). This manifests currently in the marketing of skin lightening products using terms such as bright, radiance, light and clear on the packaging because South African legislation prohibits the advertising of skin lightening products to bleach, lighten or whiten. ${ }^{14}$ All these factors continue to uphold white supremacy leading to a South African pigmen- 
tocratic society. ${ }^{15}$

Paradoxically, the use of skin lightening creams increased after South Africa achieved democracy in 1994. As a result of liberation from apartheid-era legislation and racial classificatory schemes, new spaces for the expression of identity opened up. Lightening in this way might be seen not in terms of black people aspiring to be white, but rather, free from the planters, where planters in this instance refers to the oppressors that rooted people to racial classificatory systems. ${ }^{16}$ Global aesthetic regimes continue to place emphasis on, and preference for, lighter shades of brown. Lighter shades of skin continue to inform beauty practices even in the context of black empowerment and Afropolitan movements that continually seek to rupture colonial and western domination. Consumer choice now fashions lightening as a form of human agency, where the surface of the skin can be manipulated to conform to, or resist global and local beauty standards. Capitalism is thus implicated in the process of commodification identity politics.

Today, these socio-political influences are evident by a shared view, ${ }^{17}$ Nahomie Julien that a lighter shade of brown (also referred to as yellow-bone) is the most attractive skin colour. ${ }^{17}$ For example the magazine industry bears this out, with only one woman of colour appearing as one of the top 100 sexiest women in the global men's magazine, For Him Magazine (FHM).The cosmetic industry unscrupulously advertises lightness to market products, which have the potential to endanger life. ${ }^{18} \mathrm{~A}$ conservative estimate proposes that $35 \%$ of South African women use skin lightening creams. ${ }^{19}$ In a more recent study, by Ncoza Dlova, which focused on the perception of possible benefits and risks associated with the use of skin lightening creams among Africans and Indians in Durban, $32.2 \%$ of the population admitted to using skin lightening creams. ${ }^{12}$ The use of creams is prevalent across rural and urban demographics as well as across income and class stratification. ${ }^{11}$ The phenomenon of skin-lightening is decidedly global in scope. Studies located in Asia, USA, U.K., India, China and the Caribbean indicate the prevalence of a thriving skin lightening cream industry. ${ }^{19}$ In three different African countries, the statistics demonstrate that $25 \%$ of women in Bamako, Mali a further $52 \%$ in Dakar, Senegal, and 77\% in Lagos, Nigeria use skin lighteners. ${ }^{19}$ The underlying motivations to lighten skin in in South Africa, as within an African context, drive our enquiry here.

\section{Why do people use skin light- eners?}

Some people use skin lighteners to treat dermatological conditions such as hyperpigmentary melasma, age-induced darkening and acne. Other skin disorders such as vitiligo require the supervision of a dermatologist. These treatments involve the use of hydroquinone (HQ)-containing products such as imiquimod but are under the strict guidelines of clinical use. Some consumers use skin lightening products to lighten skin colour, enhance luminescence or radiance, even out skin tone, improve the texture of the skin, to satisfy peers, to satisfy ones partner and/or to attract partners and to enhance/increase employment opportunities. ${ }^{11}$ Some others continue to lightening their skin by addiction to bleaching products. ${ }^{20}$ Some studies have shown the impact of black celebrity endorsements for skin lightening products on consumer markets. ${ }^{18}$ For example, music celebrities like Beyonce, Rhianna and Nicky Minaj, give the impression that lighter skin is beautiful skin. ${ }^{8,18}$ Even though none of these celebrities acknowledge the use of lightening products, there has been gradual lightening of their skin as can be observed in the media. While these celebrities can afford the most expensive product lines, average consumers tend to purchase creams at local suppliers, which do not comply with health regulations. ${ }^{5}$ Some consumers make their own formulations from household products combined with skin lightening products, this in an attempt to enhance the whitening effect. This dangerous mixing may result in deleterious side effects like ochronosis. ${ }^{5,8}$ This condition is characterised by localized, blue-black hyperpigmentation in the epidermis, dermis and subcutaneous layers of the skin. It is notifiable by progressive darkening in the area wherein the hydroquinone containing cream is applied. ${ }^{18}$

\section{Dangers of skin lightening products}

The efficacy of the majority of wellresearched, marketed skin lighteners on sale at brand stores are effective when used correctly work well. ${ }^{18}$ The skin lighteners available in mainstream retailers are highly efficacious, but are marketed as skin toners or moisturisers. These formulations contain regulated amounts of $\mathrm{HQ}$ and other ingredients such as retinoids and corticosteroids. According to current South African legislation, hydroquinone in skin lightening preparations are allowed up to $2 \% .^{5}$ It is crucial to note that the regulated formulations are sold with a product insert providing the necessary ingredient list and the correct usage, which should translate into the appropriate daily application. Unfortunately, products like these exceed the level of affordability for the average African consumer. Lack of affordability may be one of the most significant drivers of the black market in South Africa and Africa where unregulated - and more affordable - products flood the market. Due to the lack of product knowledge and absence of a product description, consumers rely on the reputation of the cream reinforced through positive word of mouth and consumer feedback. ${ }^{5}$ After the initial stages of application and resultant visible changes in complexion, consumers may apply more product than advised in a bid to make the product work faster and better. The consequence however results in irreversible damage to the skin, a condition known as exogenous ochronosis (Supplementary Figure S1). A more systemic, sustainable intervention is therefore needed at both the local and national governmental level before the colorism pandemic reaches exorbitant proportions. Part of the solution would be an increased awareness through scientific and social engagement as well as harnessing the influential power of the media.

\section{Influence of the media}

The media's role in contributing to the positive outcome in the war against unregulated use of skin lighteners cannot be overstated. The media plays an influential role in the purchase and use of skin lightening products. ${ }^{21}$ Fairness can be portrayed as a sign of what is idealised and as a standard for beauty and competency. Products are advertised to promote health and beauty. Billboard advertising in Africa for over 50 years portrayed whiteskinned individuals as icons of beauty, as did the print and electronic media industries. Today, in an even greater way, the media plays an influential role in how people live and how they perceive themselves. Television, magazines, newspapers schoolbooks and the likes of social media platforms, Facebook and Twitter, (Supplementary Figure S2) further emphasise the importance of image and beauty and how integral they are to achieving success. .11,18,22 $^{2}$

These platforms encourage the use of products as it presents visual stimuli where individuals with a light skin tone are portrayed as being more attractive and more likely to be successful in life. This ideology bolsters the perception that a fairer complexion is equated to material and social success (Supplementary Figure S3). Advertisements promote the idea of fairness with slogans such as Successful people, Making your dreams come true, add sparkle to your life and lighter and lovelier. Women claim that the way the television advertises skin lightening products, compels them to prefer lighter skin tones. ${ }^{11,21}$

Commercials and advertisements for skin lightening products offer the promise of 
lighter, whiter skin. To tout the skin lightening products, advertisements are usually expensively produced, featuring ultra-light celebrities or super models, and presenting (and mixing) both traditional and westernized visual signifiers to evoke atmospheres of purity, cleanliness and sophistication (Leong, 2006: pg. 169). ${ }^{4}$

These forms of tele-marketing suggest black women are unhappy, ignored by men and they suffer from low self-esteem. ${ }^{23}$ Ultimately, advertisements suggest, the lighter your skin, the more likely you are to find your dream occupation or even a suitable partner. When women are exposed to, or confronted with visual stimuli from the media, it creates a sense of anxiety and insecurity which results in them engaging in harmful forms of body beautification such as skin-lightening practices. ${ }^{17}$ Well-known South African celebrities Nomasonto Mshoza Maswanganyi (Supplementary Figure S4), a South African artist, bleached her skin because she was tired of being ugly (DRUM, 17 November 2011). ${ }^{24}$ Other celebrities such as Kelly Khumalo, Khanyi Mbau and Surisha Naidoo have also been associated with lightening their skin. Moving up towards upper Africa the artist Dencia has developed her own skin lightening product called Whitenious where rumours also arise that she herself is using the product. In contrast to these celebrities encouraging skin lightening use, Lupita Nyongong, in her acceptance speech after winning an Oscar embraced her blackness and spoke openly of her own insecurities over her dark skin and how she learned to love her skin. Celebrities carry credibility and prestige, and their use of skin lighteners are perceived as being acceptable, even encouraged. ${ }^{18}$ Individuals will go to extreme measures to change the colour of their skin. Consequently, consumers become obsessed with this practise because of the results obtained by its use and positive feelings associated with it. This can be attributed to the extent to which these products are marketed that is to improve appearance. ${ }^{21}$

\section{Biopsychosocial aspects of skin bleaching}

The biopsychosocial theoretical model has been developed by the psychiatrist Engels, in 1977. This model tries to show that many variables, biological, psychological and social, interact to better understand and explain the reality of health and disease. ${ }^{25}$ Adopting the biopsychosocial approach to or making a biopsychological review of the phenomenon of skin lightning means to underline or taking into consideration the interaction that exist between the three factors in all the process of skin bleaching: the motivation of doing it, the different practices and the effects of this practice, and even in the prevention and treatment (support) processes.

The human being would not exist without the body. The existence of human being is therefore first of all biological. This biological body is constructed on socio-cultural and psychological events of the individual. The skin is also a strong metaphor in the social sciences and embodies the realms of the aesthetic, political and economic, the social and cultural, and the genetic and phenotypic, as well as psychological worlds 26

From an Anthropological perspective, the skin has a physical reality as well as a social reality. The physical communicates shapes, sizes status which are then differentiated by culture. Clothing on skin acts as protection even though some body parts are exposed. These shape, size and surface do have a social function which then applies to extreme forms of body mutilations such as tattooing, and piercings (also known as cultural skins). These cultural skins also constitute them as being part of a group or some culture where they find a sense of belonging. Helman also refers to people as social animals in the sense that they are organised into groups that regulate and perpetuate themselves. ${ }^{27} \mathrm{He}$ argues that the persons experience as member of society that shapes his/her life of the world. In doing so it is believed that it is through one's culture that they organise and legitimizes their society. He describes culture as how humans organise themselves and the way they view the world which they inhabit. Therefore in order to understand humans we need to study their society and their culture. ${ }^{27}$

Additionally the skin can also be seen as the social surface of the self. Terence Turner's concept of 'social skin' resonates in this case, wherein skin itself acts as an interface for political, cultural and social identity. The proliferation of skin-lightening creams emphasizes the importance of classification through skin-colour, stigma and preferences for lighter skin in an increasingly globalized world. He emphasizes that on a macro-social level, the conventionalized modifications of skin that comprise the social skin define, not individuals, but categories or classes of individuals thus claiming that the social skin becomes the boundary between social classes (Turner, 2012:503). ${ }^{28}$ That means that the skin is an element of belonging, of classification, recognition, distinction and pride. In essence the skin is a marker of our identity.

Skin bleaching is the use of cosmetics lightening products on the skin to look lighter. This practice sometime has negative effects as we said, and this effects side can have an impact on our body image and our self image

The practice of skin-lightening may be deeply rooted in an individual's overall emotional and cognitive evaluation of his/her own worth (self-esteem), their collections of belief about themselves and forces that influence thoughts, behaviour and personality. ${ }^{11}$ The desire to lighten one's skin is related to some aspects of self-hate (extreme dislike or hatred against oneself) and low self-esteem. ${ }^{11}$ Even though colonialism and apartheid has the transgenerational psychological scars still persist and have been internalized by many. ${ }^{11}$ Many women still regard lighter skin as beautiful and associated dark skin with negative connotations such as evil, disease, dirt ugliness etc. ${ }^{13}$ The hierarchy of women in terms of lightness of skin also known as pigmentocracy employs hegemonic ideals of beauty, influenced by the privileges of white supremacy established historically. Many individual mimic the behaviour and attitudes of others with the hope of being like them. ${ }^{3}$ For example many women compare themselves with celebrities and turn to skin lighteners because they are dissatisfied with their appearance and are under the impression that they could be just as successful as the celebrities engaging in skin-lightening practices. ${ }^{5}$ In that sense skin-lightening practices can be perceived as an external (social) factor which dictates standards of beauty because having a light skin complexion is associated with elegance, beauty, attractiveness especially towards the opposite sex. Lightness and darkness have moral connotations for example; whiteness or lightness can be associated with youth, innocence, purity, virginity, spirituality and vulnerability, whereas darkness can refer to threat, aggression, danger, virility. Individuals who are insecure, suffering from low self- esteem are more likely to engage in skin-lightening practices than those individuals who are more confident in their skin. ${ }^{13}$ Skin lightening is a global phenomenon but has there been any attempt to reduce the practice of skin lightning?

\section{Review on measures to reduce skin lightening}

Despite the bans and existing health campaigns, the practice of skin lightening continues to grow. There is a need for greater government bans as well as control on the availability of skin lighteners, the marketing and sale thereof and well as the active ingredients found in these products. ${ }^{2,29}$ Not only should government be involved, there should also be more awareness on the dangers associated with using skin lightening products. ${ }^{30}$ This can be done through educational public messages, health workers and the media. ${ }^{2}$

In addition social marketing in combating self-esteem issues has been proposed to 
reduce the risk that it may pose health risks, as they relate to skin alterations. Social marketing is described as a tool that uses the concepts of commercial marketing to create positive social change. It is founded on the idea that media can shape popular perception and, thus promotes positive behaviour change by marketing ideas of products. Therefore by promoting ideas around positive self-esteem, public health interventions can better address skin toning alterations. ${ }^{31}$

\section{Conclusions}

In summary, we reviewed the effects of skin lightening cream. The history of skin- lightening practices were discussed by reviewing colonialism and apartheid as mediating factors in skin lightening use age. We also shed light on the reasons for skin lightening use and the dangers behind inappropriate application thereof. The media portray light skin desirable and beautiful and advertise skin lightening products as a means to solve problem skin. In their marketing strategies they use models, celebrities and high profile individuals to convey messages of lightness, beauty, wealth etc. The psychosocial effects on the consumer revealed that as a result of internalising the effects of colonialism and apartheid many individuals use skin lightening creams as a means to fit in the still much dominated white supremacy. Lastly there is a great need for stricter government control and policy development in the marketing and distribution of products together with educational programmes to create awareness on the health risk posed by skin lightening products.

\section{References}

1. Charles C. Skin bleaching, self-hate, and black identity in Jamaica. J Black Studies 2003;33:711-28.

2. De Souza MM. The concept of Skin Bleaching in Africa and its devastating health implications. Clin Dermatol 2008;26:27-9.
3. Jablonski N. Living color: the biological and social meaning of skin color. University of California press Berkley and Los Angeles; 2012.

4. Leong S. Who's the fairest of them all? Television ads for skin-whitening cosmetics in Hong Kong. Asian Ethnicity 2008;72:167-81.

5. Dlova N, Hendricks N, Martincgh B. Skin lightening creams used in Durban, South Africa. Soc Dermatol 2012;51:51-3.

6. Goldin, I. The poverty of coloured labour preference: economics and ideology in the Western Cape. SALDRU Working Paper 59. Cape Town: SALDRU; 1984.

7. Levine S. You strike the women, you strike the rock. Thesis in anthropology, Bard College, New York; 1984.

8. Smart KS. Into the causes and effects of skin bleaching use in the African community. Iletocpn Creative Thinking; 2012.

9. Bellow $S$, Alster T. Treatment of ochronosis with a Q switched alexandrite (755) laser. Dermatol Surg 2004;30:555-8.

10. Mbeki G. South Africa: the peasants revolt. London: International Defence Aid Fund; 1984.

11. Hamed S, Tayyem R, Nimer N, et al. Skin lightening practice among women living in Jordan: prevelance, determinants, and user's awareness. Int $\mathrm{J}$ Dermatol 2010;49:414-20.

12. Dlova N, Hamed S, Tsoka-Gwegweni J, et al. Women's perception of the benefits and risks of skin-lightening creams in two South African communities. J Cosmet Dermatol 2014;13:236-41.

13. Fanon F. Black skin, white masks. New York; CL Markmann; 1952.

14. Thomas LM. Skin lighteners in South Africa: transnational entanglements and technologies of the self. In: Glenn EN, ed. Shades of difference: why skin color matters. Stanford: Stanford University Press; 2009. pp 188-210.

15. Westerhof W. A few more grains of melanin. Int J Dermatol 1997;36:573-4.

16. Rwomire A, Nyamnjoh, FB. Challenges and responsibilities of social research in Africa: ethical issues. Addis Ababa: OSSREA; 2007.

17. Julien N. Skin bleaching in South Africa: a result of colonialism and apartheid? Discovery: Georgia State Hon Col Undergrad Research J 2014;2:1-4

18. Glenn, E. Yearning for lightness: transnational circuits in the marketing and consumption of skin lighteners. Gender Soc 2008;22:281-302.

19. National Toxicology Program. Nomination profile: hydroquinone. 2009. Available from: https://ntp.niehs.nih.gov/ntp/ noms/support_docs/hydroquinone_may20 09.pdf

20. Petit A. La dimension addictive de la dépigmentation volontaire, Université Paris 13, LSHS Villetaneuse, SMBH Bobigny, 2006-2007.

21. Lewis KM, Robkin N, Gaska K, Njoki LC. Investigating motivations for women's skin bleaching in Tanzania. Psych Women Quarter 2011;35:29-37.

22. Kpanake L, Mullet E. Motives for skin bleaching among West Africans. H\&PC Today 2011;6:6-9.

23. Olumide Y, Akinkugbe A, Altraide D, et al. Complications of chronic use of skin lightening cosmetics. Int J Dermatol 2008;47: 344-53.

24. Drum team. I am tired of being black. Drum Magazine, 17 November 2011.

25. Santiago-Delefosse M. Psychologie de la santé. Perspectives qualitatives et cliniques; pierre. Mardaga éditeur, 2002.

26. Breton D. Anthropologie du corps et modernité, Presses universitaires de France, coll. Quadrige Essais Débats , 2008.

27. Helman. Culture, Health and Illness. Butterworth Heinemann: Oxford; 2000.

28. Turner TS. The Social Skin. HAU: J Ethno Theo 2012;2:486-504.

29. Kooyers TJ, Westerhof W. Toxicology and health risks of hydroquinone in skin lightening formulations. J Eur Acad Dermatol Venereol 2006;20:777-80.

30. Mahé A. Ly F, Perret J L. Systemic complications of the cosmetic use of skin-bleaching products. Int J Dermatol 2005;44:37-8.

31. Karelas GD. Social Marketing self-esteem: a socio-medical approach to high-risk and skin tone alteration activities. Int $\mathrm{J}$ Dermatol 2011;50:590-2. 